\title{
Analysis of seven maternal polymorphisms of genes involved in homocysteine/folate metabolism and risk of Down syndrome offspring
}

Iris Scala, $M D^{1}$, Barbara Granese, $P h D^{1}$, Maria Sellitto, $M D^{1}$, Serena Salomè, $M D^{1}$, Annalidia Sammartino, $M D^{2}$, Antonio Pepe, $P h D^{1}$, Pierpaolo Mastroiacovo, $\mathrm{MD}^{3}$, Gianfranco Sebastio, $\mathrm{MD}^{1}$, and Generoso Andria, $M D^{1}$

\begin{abstract}
PURPOSE: We present a case-control study of seven polymorphisms of six genes involved in homocysteine/folate pathway as risk factors for Down syndrome. Gene-gene/allele-allele interactions, haplotype analysis and the association with age at conception were also evaluated. METHODS: We investigated 94 Down syndrome-mothers and 264 control-women from Campania, Italy. RESULTS: Increased risk of Down syndrome was associated with the methylenetetrahydrofolate reductase (MTHFR) $1298 \mathrm{C}$ allele (OR 1.46; 95\% Cl 1.02-2.10), the MTHFR $1298 \mathrm{CC}$ genotype (OR 2.29; 95\% Cl 1.06-4.96), the reduced-folate-carrier1 (RFC1) 80G allele (1.48; 95\% Cl 1.05-2.10) and the RFC1 $80 \mathrm{GG}$ genotype (OR 2.05; 95\% Cl 1.03-4.07). Significant associations were found between maternal age at conception $\geq 34$ years and either the MTHFR $1298 \mathrm{C}$ or the RFC $180 \mathrm{G}$ alleles. Positive interactions were found for the following genotype-pairs: MTHFR 677TT and 1298CC/CA, 1298CC/CA and RFC1 80 GG/GA, RFC1 80 GG and methylenetetrahydrofolate-dehydrogenase 1958 AA. The 677-1298 T-C haplotype at the MTHFR locus was also a risk factor for Down syndrome $(P=0.0022)$. The methionine-synthase-reductase $A 66 \mathrm{G}$, the methionine-synthase $\mathrm{A} 2756 \mathrm{G}$ and the cystathionine-beta-synthase 844 ins 68 polymorphisms were not associated with increased risk of Down syndrome. CONCLUSION: These results point to a role of maternal polymorphisms of homocysteine/folate pathway as risk factors for Down syndrome. Genet Med 2006:8(7):409-416.
\end{abstract}

Key Words: Down syndrome, polymorphism, homocysteine, folates, gene-gene interaction

Down syndrome (DS) is caused by trisomy of either the entire amount, or a critical portion of chromosome 21. Birth prevalence increases with maternal age from 0.6 in 1,000 live births at 20 years up to 11 in 1,000 live births at 40 years. ${ }^{1}$ In $95 \%$ of cases, DS is caused by a meiotic error occurring at meiosis I or II, mainly of maternal origin. ${ }^{2}$

Despite huge efforts, the mechanisms underlying meiotic nondisjunction and the contribution of maternal age on trisomy 21 are poorly understood. Some studies suggest that genomic DNA hypomethylation may be associated with chromosomal instability and abnormal segregation..$^{3-5}$ On the other hand, impairment of folate metabolism has been causally related to both DNA hypomethylation and abnormal purine synthesis. ${ }^{6}$ This combination leads to chromosomal breakage and deficient DNA repair surveillance that increase the degree of genomic instability. ${ }^{7}$ Polymorphisms of genes of the homocysteine/folate metabolism may interfere with folate homeostasis,

\footnotetext{
From the ${ }^{1}$ Department of Pediatrics, the ${ }^{2}$ Department of Gynecology and Obstetrics, Federico II University of Naples, via S. Pansini 5, 80131 Naples, Italy; and the ${ }^{3}$ International Centre of Birth Defects, via P. Albertelli 9, 00195 Rome, Italy.

Professor Generoso Andria, Department of Pediatrics, Federico II University of Naples, Via S. Pansini 5, 80131, Naples, Italy.

Submitted for publication December 24, 2005.

Accepted for publication April 11, 2006.
}

DOI: 10.1097/01.gim.0000228206.21793.82 cellular methylations or both. Methylenetetrahydrofolate reductase (MTHFR) is a critical regulator of cellular methylations by catalyzing the conversion of 5,10 methylenetetrahydrofolate to 5-methyltetrahydrofolate, the methyl donor for the remethylation of homocysteine (Hcy) to methionine $(\text { Met })^{8}$ (Fig. 1). This reaction is important for the synthesis of S-adenosylmethionine (SAM), the major intracellular methyl donor for DNA, protein and lipid methylation. The MTHFR $677 \mathrm{~T}$ variant causes a reduced MTHFR activity and an increased need of folic acid to allow the remethylation of Hcy to Met. A second common MTHFR mutation, the A1298C transversion, causes decreased MTHFR activity. Both the 1298C and the 677T polymorphisms may affect DNA methylation. ${ }^{9}$ The remethylation of Hcy to Met is catalyzed by the methionine synthase (MTR) enzyme, maintained in its functional state by the methionine synthase reductase (MTRR) reducing system. Two polymorphisms have been described in the MTR and the MTRR genes, A2756G and A66G, respectively, the former being associated with aberrant methylation in the homozygous state. ${ }^{10}$ Cystathionine-beta-synthase (CBS) is a key enzyme in the transsulfuration of Hcy to cystathionine. The 844 ins 68 polymorphism, carried by nearly $10 \%$ of the general population, may cause lower tHcy levels compared to noncarriers, in particular after methionine loading. ${ }^{11} \mathrm{~A}$ common mutation $(\mathrm{A} 80 \mathrm{G})$ of the reduced-folate-carrier gene (RFC1), leading to nonsignificantly decreased plasma folate levels, has been 


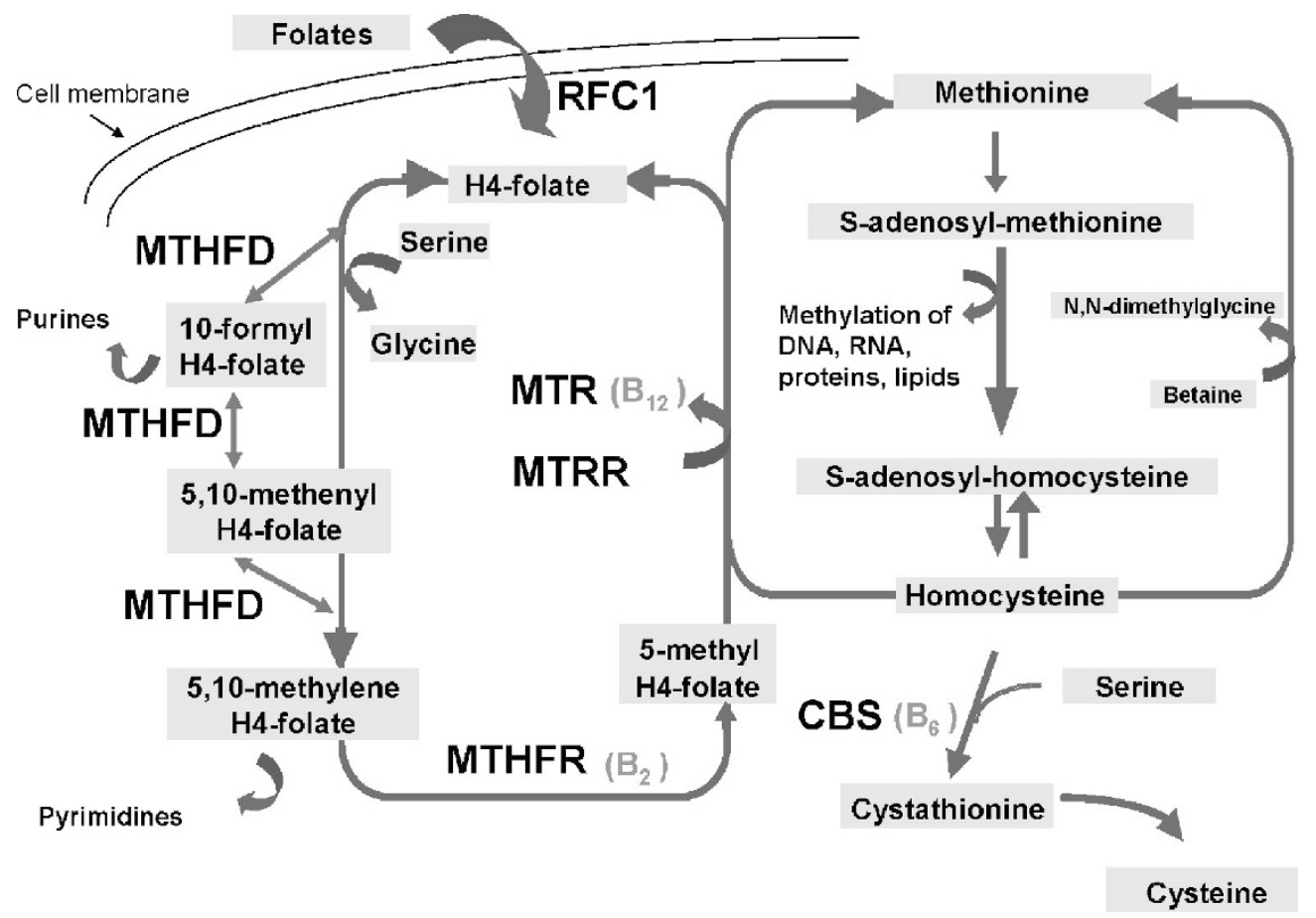

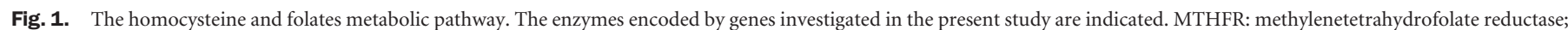

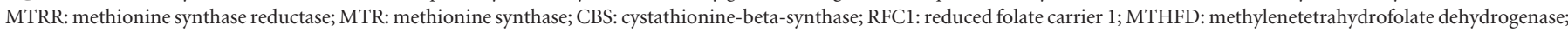
$\mathrm{B}_{12}$ : vitamin $\mathrm{B}_{12} ; \mathrm{B}_{2}$ : vitamin $\mathrm{B}_{2} ; \mathrm{B}_{6}$ : vitamin $\mathrm{B}_{6}$.

recently reported. ${ }^{12}$ Finally, a G1958A polymorphism was identified in the methylenetetrahydrofolate dehydrogenase (MTHFD) gene, which encodes for a trifunctional enzyme that catalyzes the conversion of tetrahydrofolate to 10 -formyl, 5,10-methenyl, and 5,10-methylenetetrahydrofolate, donor cofactors for nucleotide and DNA biosynthesis. ${ }^{13}$

Based on this evidence, a number of studies from distinct geographic regions evaluated the role of polymorphisms of genes of Hcy/folate metabolism as maternal risk factors for DS with inconsistent results. Specifically, the maternal MTHFR C677T polymorphism was associated with increased risk of DS in the USACanadian and Brazilian populations ${ }^{14-17}$ but not in reports from Ireland, France, Turkey, Japan, and two Italian regions. ${ }^{18-24}$ Further, two studies found an association between the MTRR 66GG genotype and increased risk of DS, particularly when associated with the MTHFR C677T variant, ${ }^{15,18}$ while a study in a Sicilian population failed to confirm such association. ${ }^{23}$ On the other hand, the Sicilian study first reported the effect of the MTR A2756G variant on the risk of DS that was stronger when associated with the MTRR A66G polymorphism. The MTHFR A1298C variant was associated with increased risk of DS in one study ${ }^{16}$ while four other groups reported negative results. ${ }^{17,21,23,24}$ The RFC1 A80G and the CBS 844ins68 polymorphic variants were not associated with DS in one ${ }^{24}$ and in two studies, ${ }^{17,24}$ respectively. The MTHFD G1958A polymorphism, previously associated with increased risk of neural tube defects, ${ }^{25}$ has not been investigated as a risk factor for DS, yet.

Here we present a case-control study in a homogeneous population from Campania, Italy, of seven polymorphic gene variants of Hcy/folate metabolism. Gene-gene/allele-allele interactions and MTHFR haplotype analysis are also reported. Finally, all gene polymorphisms were analyzed according to maternal age at conception to assess whether specific genetic factors could contribute to the maternal age-effect on chromosomal nondisjunction.

\section{SUBJECTS AND METHODS}

\section{Study population}

Blood samples were collected from a total of 94 women who had given birth to children with kariotypically confirmed full trisomy 21. Mothers were recruited from the Department of Pediatrics, Federico II University of Naples, the regional referral center for DS. A total of 264 control-women were enrolled at the same University Hospital as follows: healthy women from the Blood Donor Center, women referring to the Department of Gynecology and Obstetrics for routine pregnancy checks and DNA samples from healthy women collected at the Department of Pediatrics. Among the control group, no history of abnormal pregnancy outcome was reported. All case and control women belong to the same ethnicity (Caucasian). Moreover, as a geographical variation among different Italian regions has been described for the MTHFR C677T polymorphism, ${ }^{26}$ only case and control women born in the Campania region, Southern Italy, were included in the analysis. To calculate the age at conception, all case-mothers were interviewed for date of birth, age at delivery and gestational age of the offspring. Among the control group, these data were available and/or complete for a total of 134 subjects out of 264 . The mean 
age at conception of case-mothers was $32.4 \pm 6.3$ years. The mean age at conception of control-mothers was $30 \pm 5.6$ years as calculated at the time of the last pregnancy. The distribution of genotype frequencies of the 134 control-mothers was comparable to those of the total control group. A potential bias deriving from hospital-based case-control studies was minimized according to the recommendations by Wacholder et al. and Schulz et al. ${ }^{27,28}$ All participants were recruited after informed written consent, according to the recommendations of the University ethical committee for studies that do not involve therapeutic trials or major invasive procedures.

\section{Specimen collection and biochemical analysis}

Genomic DNA was isolated from peripheral blood samples by NucleoSpin Blood kit (Macherey-Nagel), according to the manufacturer's instructions. Venous blood samples collected in EDTA-containing vacutainer tubes were centrifuged within 1 hour at 2,000g for 10 minutes and plasma aliquots stored at $-70^{\circ} \mathrm{C}$. Total plasma homocysteine (tHcy) was determined by high-performance liquid chromatography (HPLC).

\section{Detection of mutations}

MTHFR C677T: To enhance the sensitivity of the original method, ${ }^{8}$ we modified the forward primer by introducing a new Hinfl site as an internal control of the Hinfl digestion. Primers for amplification were: forward $5^{\prime}$-ggtggaggccagcctctcctgactctcatccctattg-3', reverse $5^{\prime}$-aggacggtgcggtgagagtg- $3^{\prime}$. PCR conditions were: denaturation $94^{\circ} \mathrm{C}$ ( 1 minute), annealing $53^{\circ} \mathrm{C}$ ( 1 minute), elongation $72^{\circ} \mathrm{C}$ ( 1 minute) for a total of 39 cycles. PCR amplification generated a $294 \mathrm{bp}$ fragment. The presence of the T-allele generated a Hinfl site. After a Hinfl digestion of the $294 \mathrm{bp} \mathrm{PCR}$ product, the mutant allele was detected as 25,94 and $175 \mathrm{bp}$ fragments. The $25 \mathrm{bp}$ fragment represents the internal control of the Hinfl digestion.

MTHFR A1298C: The mutation was detected using primers and conditions described by van der Put et al., 2000. ${ }^{29}$

MTRR A66G: Since this mutation does not create or abolish a restriction site, a PCR-dependent diagnostic test was designed by taking advantage of a modified sense primer that created a NdeI site when the 66A allele was present (in the forward primer a $\mathrm{C}$-underlined-replaces an $\mathrm{A}$ ). In the antisense primer, an A (underlined) was introduced to create another NdeI site as internal control for digestion. Primers for amplification were: forward $5^{\prime}$-CAGCAGGGACAGGCAAAGGCCATCGCAGAAGACAT-3', reverse 5' -ctggtgatatcttactataccatatgaacaaacac- $3^{\prime}$. PCR conditions were: denaturation $94^{\circ} \mathrm{C}$ ( 1 minute), annealing $56^{\circ} \mathrm{C}\left(1\right.$ minute), elongation $72^{\circ} \mathrm{C}$ (1 minute) for a total of 39 cycles. The PCR fragment was 254 bp long. When the $66 \mathrm{G}$ allele was present, the NdeI site was abolished and a $230 \mathrm{bp}$ amplicon was obtained. The $24 \mathrm{bp}$ fragment represented the internal control of digestion. When the 66A allele was present, a second NdeI site was created and a $196 \mathrm{bp}$ fragment was obtained after digestion.

CBS 844ins68: Primers for amplification were: $5^{\prime}$-CTGCCTTGAGCCCTGAAGCC-3'， 5'-CTGGACTCGACCTACCGTCCT-3'. PCR conditions were: denaturation $94^{\circ} \mathrm{C}$ (1 minute), annealing $60^{\circ} \mathrm{C}$ ( 1 minute), elongation $72^{\circ} \mathrm{C}$ ( 1 minute) for a total of 39 cycles. When present, the 844ins68 insertion caused a $+68 \mathrm{bp}$ shifted band of the PCR product (242 bp instead of $174 \mathrm{bp})$.

MTR A2756G: The mutation creates a HaeIII site. To rely on an internal control, we introduced a HaeIII site by replacing an A with a $G$ (underlined) in the antisense oligonucleotide. Primers for amplification were $5^{\prime}$-cagTGTTCCCAGCTGTTAGATG-3', 5' -gggaacttaagacactgaaggcctctg-3'. PCR conditions were: denaturation $94^{\circ} \mathrm{C}\left(1\right.$ minute), annealing $56^{\circ} \mathrm{C}(1$ minute), elongation $72^{\circ} \mathrm{C}$ ( 1 minute) for a total of 39 cycles. When the A-allele was present, a $252 \mathrm{bp}$ fragment was identified; when the G-allele was present, the PCR product was digested in 169 and 83 bp fragments.

RFC1 A80G: The mutation creates an HhaI site. Primers for amplification were: forward $5^{\prime}$-gcggggtagggaggcctgcag- $3^{\prime}$ and reverse $5^{\prime}$-GCTCTCCCCTGGCCGTATCTGCGCC-3'. The antisense oligonucleotide contains an HhaI site (underlined) used as internal control of the HhaI digestion. PCR conditions were: denaturation $94^{\circ} \mathrm{C}$ (1 minute), annealing $60^{\circ} \mathrm{C}(1$ minute), elongation $72^{\circ} \mathrm{C}$ ( 1 minute) for a total of 39 cycles. The PCR amplification generated a $247 \mathrm{bp}$ fragment. The mutant allele was detected by the presence of 21,37 and $189 \mathrm{bp}$ fragments. The $21 \mathrm{bp}$ fragment represented the internal control of the Hhal digestion.

MTHFD G1958A: The G->A transition abolishes a MspI restriction site. Primers for amplification were: forward $5^{\prime}$-cctggtttccacagGGCACTC-3', and reverse $5^{\prime}$-CCACGTGGGGGCAGAGGCCGGAATACCGG-3'. The antisense oligonucleotide contained a MspI site as internal digestion control. The forward primer included an intronic region to avoid the amplification of the MTHFD intronless pseudogene on chromosome X. PCR conditions were: denaturation $94^{\circ} \mathrm{C}$ ( 1 minute), annealing $60^{\circ} \mathrm{C}\left(1\right.$ minute), elongation $72^{\circ} \mathrm{C}(1$ minute) for a total of 36 cycles. The PCR amplification generated a $310 \mathrm{bp}$ fragment. After MspI treatment of the PCR product, the A-allele was detected by the presence of 282 and $28 \mathrm{bp}$ fragments while the $\mathrm{G}$ allele was identified by the presence of 196,86 and $28 \mathrm{bp}$ fragments.

A quality control check for all the polymorphisms included direct sequencing of $10 \%$ of samples (ABI-PRISM 377 DNA Sequencer). Not all loci where amplified from every subject due to a limited DNA quantity or to technical problems with PCR amplification.

\section{Statistical analysis}

Allele frequencies were calculated for each polymorphism and the differences between mothers of children with DS and controls were determined by using the Pearson's $\chi^{2}$ test. Odds ratios for both the heterozygous and homozygous mutant genotypes, as compared with the wild types, were calculated as the measure of the association between the heterozygous and homozygous mutant genotypes and a DS-affected pregnancy by standard $2 \times 2$ contingency tables (EpiInfo software version 3.3, 2004). The Hardy-Weinberg equilibrium of each polymorphism in cases and controls was tested by $\chi^{2}$ test. Results of 
continuous data were expressed as medians \pm SD; comparisons between groups were performed by Mann-Whitney Utest. To explore the association between polymorphisms and maternal age at conception we divided the data-set into agequartiles, based on the distribution among controls (first quartile $\leq 26$ years, second quartile $27-30$ years, third quartile 31-33 years; fourth quartile $\geq 34$ years) (SPSS software, version 12.0). To explore the possible interactions between mutant genotypes, we used the "two-by-four" approach, as reported elsewhere. ${ }^{30}$ MTHFR haplotypes were inferred only for subjects with complete genotyping data (94 cases, 256 controls) using an accelerated Expectation-Maximization (EM) algorithm, which creates highly accurate population frequency estimates of the phased haplotypes based on the maximum likelihood as determined from the unphased input. ${ }^{31}$ Fisher's exact test was used when appropriate. To correct for inflated alfa error resulting from multiple group comparisons within sets, we used the modified Bonferroni test provided by Keppel $^{32}$ that corrects for the number of chi-square tests and the degrees of freedom (df) involved in each test according to the formula: alfa $($ new $)=1-(1-\text { alfa })^{\mathrm{df}} /$ number of comparisons. The adjusted $P$-value was considered as the new cut-off to determine statistical significance.

\section{RESULTS}

\section{Allele frequencies and risk of Down syndrome}

The frequencies of the MTHFR C677T, MTHFR A1298C, MTRR A66G, MTR A2756G, RFC1 A80G, MTHFD G1958A and CBS 844ins68 allelic variants were evaluated in mothers of DS children (cases) and controls. As shown in Table 1, the frequency of the MTHFR $1298 \mathrm{C}$ allele in cases $(38.8 \%$ ) was significantly higher than in controls $(30.3 \%)$, with a 1.46 -fold increased risk of having a DS offspring. Similarly, mothers with the RFC1 $80 \mathrm{G}$ allelic variant had a 1.48-fold increased risk of having a child with DS. No significant associations were found for the other polymorphic variants under study.

\section{Genotype analysis and risk of Down syndrome}

The analysis of the MTHFR, MTRR, MTR, RFC1, MTHFD and CBS mutant genotypes in the case and control groups showed again an association with the MTHFR A1298C and RFC1 A80G mutations (Table 2). These data indicate a 2.29fold increased risk of DS in mothers with the $1298 \mathrm{~A}->\mathrm{C}$ substitution on both alleles compared to wild type. The presence of the RFC1 $80 \mathrm{GG}$ genotype was associated with a 2.05 -fold

Table 1

Allele frequencies of MTHFR C677T, MTHFR A1298C, MTRR A66G, MTR A2756G, RFC1 A80G, MTHFD G1958A and CBS 844ins68 polymorphisms in mothers of DS children (cases) and controls

\begin{tabular}{|c|c|c|c|c|}
\hline Polymorphism & Allele & Cases (\%) & Controls (\%) & OR $(95 \% \mathrm{CI})$ \\
\hline \multirow[t]{3}{*}{ MTHFR C677T } & $\mathrm{T}$ & $87(46.3)$ & $239(46.7)$ & $0.98(0.69-1.39)$ \\
\hline & $\mathrm{C}$ & $101(53.7)$ & $273(53.3)$ & Reference \\
\hline & Total & 188 & 512 & \\
\hline \multirow[t]{3}{*}{ MTHFR A1298C } & $\mathrm{C}$ & $73(38.8)$ & $158(30.3)$ & $1.46(1.02-2.10)^{a, c}$ \\
\hline & A & $115(61.2)$ & $364(69.7)$ & Reference \\
\hline & Total & 188 & 522 & \\
\hline \multirow[t]{3}{*}{ MTRR A66G } & G & $84(45.2)$ & $245(47.7)$ & $0.90(0.64-1.28)$ \\
\hline & A & $102(54.8)$ & $269(52.3)$ & Reference \\
\hline & Total & 186 & 514 & \\
\hline \multirow[t]{3}{*}{ MTR A2756G } & G & $23(12.2)$ & $79(15.3)$ & $0.77(0.46-1.31)$ \\
\hline & A & $165(87.8)$ & 439 (84.7) & Reference \\
\hline & Total & 188 & 518 & \\
\hline \multirow[t]{3}{*}{ RFC1 A80G } & G & $93(49.5)$ & 209 (39.7) & $1.48(1.05-2.10)^{b, c}$ \\
\hline & A & $95(50.5)$ & $317(60.3)$ & Reference \\
\hline & Total & 188 & 526 & \\
\hline \multirow[t]{3}{*}{ MTHFD G1958A } & A & $87(48.3)$ & $239(49.0)$ & $0.97(0.68-1.39)$ \\
\hline & G & $93(51.7)$ & $249(51.0)$ & Reference \\
\hline & Total & 180 & 488 & \\
\hline \multirow[t]{3}{*}{ CBS 844ins68 } & Ins + & $11(5.9)$ & $35(6.6)$ & $0.88(0.41-1.84)$ \\
\hline & Ins - & $177(94.1)$ & 493 (93.4) & Reference \\
\hline & Total & 188 & 528 & \\
\hline
\end{tabular}

${ }^{a} P=0.04 ;{ }^{b} P=0.02$.

${ }^{c}$ The difference is significant using $P$-value adjusted for inflated error (adjusted $P=0.043$ ). 
Table 2

Genotype frequencies of MTHFR C677T, MTHFR A1298C, MTRR A66G, MTR A2756G, RFC1 A80G, MTHFD G1958A and CBS 844ins68 polymorphisms in mothers of DS children (cases) and controls

\begin{tabular}{|c|c|c|c|c|}
\hline Polymorphism & Genotype & Cases (\%) & Controls (\%) & Odds Ratio (95\% CI) \\
\hline \multirow[t]{4}{*}{ MTHFR C677T } & $\mathrm{TT}$ & $24(25.5)$ & $57(22.2)$ & $1.01(0.51-1.99)$ \\
\hline & CT & $39(41.5)$ & $125(48.8)$ & $0.74(0.41-1.34)$ \\
\hline & $\mathrm{CC}$ & $31(33.0)$ & $74(29.0)$ & 1 (reference) \\
\hline & Total & 94 & 256 & \\
\hline \multirow[t]{4}{*}{ MTHFR A1298C } & $\mathrm{CC}$ & $17(18.1)$ & $25(9.6)$ & $2.29(1.06-4.96)^{a, c}$ \\
\hline & $\mathrm{AC}$ & $39(41.5)$ & $108(41.4)$ & $1.22(0.70-2.10)$ \\
\hline & AA & $38(40.4)$ & $128(49.0)$ & 1 (reference) \\
\hline & Total & 94 & 261 & \\
\hline \multirow[t]{4}{*}{ MTRR A66G } & GG & $19(20.4)$ & $57(22.2)$ & $0.82(0.39-1.71)$ \\
\hline & $\mathrm{AG}$ & $46(49.5)$ & $131(51.0)$ & $0.87(0.48-1.56)$ \\
\hline & AA & $28(30.1)$ & $69(26.8)$ & 1 (reference) \\
\hline & Total & 93 & 257 & \\
\hline \multirow[t]{4}{*}{ MTR A2756G } & GG & $1(1.1)$ & $3(1.2)$ & $0.85(0.02-10.76)$ \\
\hline & AG & $21(22.3)$ & $73(28.2)$ & $0.73(0.40-1.32)$ \\
\hline & AA & $72(76.6)$ & $183(70.6)$ & 1 (reference) \\
\hline & Total & 94 & 259 & \\
\hline \multirow[t]{4}{*}{ RFC1 A80G } & GG & $26(27.7)$ & $48(18.2)$ & $2.05(1.03-4.07)^{b}$ \\
\hline & AG & $41(43.6)$ & $113(43.0)$ & $1.37(0.76-2.48)$ \\
\hline & AA & $27(28.7)$ & $102(38.8)$ & 1 (reference) \\
\hline & Total & 94 & 263 & \\
\hline \multirow[t]{4}{*}{ MTHFD G1958A } & AA & $18(20.0)$ & $51(21.0)$ & $0.94(0.42-2.09)$ \\
\hline & AG & $51(56.7)$ & $137(56.1)$ & $0.99(0.53-1.88)$ \\
\hline & GG & $21(23.3)$ & $56(22.9)$ & 1 (reference) \\
\hline & Total & 90 & 244 & \\
\hline \multirow[t]{3}{*}{ CBS 844ins68 } & Ins $+/-$ & $11(11.7)$ & $35(13.3)$ & $0.87(0.39-1.87)$ \\
\hline & Ins $-/-$ & $83(88.3)$ & $229(86.7)$ & 1 (reference) \\
\hline & Total & 94 & 264 & \\
\hline
\end{tabular}

${ }^{a} P=0.03 ;{ }^{b} P=0.04$.

${ }^{\prime}$ The difference is significant using $P$-value adjusted for inflated error (adjusted $P=0.040$ ). The distributions of all genotypes are in the Hardy-Weinberg equilibrium. No homozygosity for the CBS844ins68 insertion was found in the study population.

increased risk of DS. No significant differences were found for the remaining analyzed genotypes.

\section{MTHFR A1298C, RFC1 A80G polymorphisms and maternal age at conception}

Ninety-four cases and 134 control mothers were stratified in three groups by age at conception, i.e., maternal age $\leq 26$ years, $27-33$ years and $\geq 34$ years, where the first group corresponded to the first quartile, the second group to the second and third quartiles and the third group to the fourth quartile (Table 3 ).

\section{MTHFR A1298C}

Results indicate an association between the 1298C allele and mothers of children with DS aged $\geq 34$ years (upper quartile) at the time of conception. In the same group, the presence of the 1298 CC or CA genotype (compared to 1298AA genotype) was associated to a 2.98 -fold increased risk of DS (OR 2.98; $95 \%$ CI $1.08-8.37)$.

\section{RFC1 A80G}

Table 3 shows the association between the RFC1 80G allele and maternal age at conception $\geq 34$ years. Also, the $80 \mathrm{GG}$ genotype (compared to the $80 \mathrm{AA}$ genotype) was associated with a 5.12 -fold increased risk of DS in the same age-subgroup with a trend toward significance (OR 5.12; 95\% CI 0.99-33.88).

No significant associations were demonstrated for the other genotypes (data not shown). 
Table 3

MTHFR 1298C and RFC1 80G alleles, maternal age at conception and risk of DS in case-mothers versus controls

\begin{tabular}{|c|c|c|c|c|}
\hline $\begin{array}{l}\text { Age } \\
\text { (quartiles) }\end{array}$ & $\begin{array}{c}\text { MTHFR } \\
\text { A1298C (Alleles) }\end{array}$ & $\begin{array}{c}\text { Cases } \\
\mathrm{N}=94\end{array}$ & $\begin{array}{l}\text { Controls } \\
\mathrm{N}=134\end{array}$ & OR $(95 \% \mathrm{CI})$ \\
\hline \multirow[t]{2}{*}{$\leq 26$ years } & $\mathrm{C}$ & 13 & 21 & $1.22(0.49-3.02)$ \\
\hline & A & 27 & 53 & \\
\hline \multirow[t]{2}{*}{$27-33$ years } & $\mathrm{C}$ & 18 & 47 & $0.84(0.41-1.73)$ \\
\hline & A & 36 & 79 & \\
\hline \multirow[t]{3}{*}{$\geq 34$ years } & $\mathrm{C}$ & 42 & 14 & $3.12(1.4-6.80)^{a, c}$ \\
\hline & A & 52 & 54 & \\
\hline & $\begin{array}{l}\text { RFC1 A80G } \\
\text { (Alleles) }\end{array}$ & $\begin{array}{c}\text { Cases } \\
\mathrm{N}=94\end{array}$ & $\begin{array}{l}\text { Controls } \\
\mathrm{N}=134\end{array}$ & OR $(95 \% \mathrm{CI})$ \\
\hline \multirow[t]{2}{*}{$\leq 26$ years } & G & 17 & 33 & $0.92(0.39-2.14)$ \\
\hline & A & 23 & 41 & \\
\hline \multirow[t]{2}{*}{$27-33$ years } & G & 27 & 48 & $1.63(0.81-3.25)$ \\
\hline & A & 27 & 78 & \\
\hline \multirow[t]{2}{*}{$\geq 34$ years } & G & 49 & 24 & $2.00(1.00-3.99)^{b, c}$ \\
\hline & A & 45 & 44 & \\
\hline
\end{tabular}

${ }^{a} P=0.002 ;{ }^{b} P=0.04$.

${ }^{\circ}$ The difference is significant using $P$-value adjusted for inflated error (adjusted $P=0.044$ ). The first category corresponds to the first quartile, the second category to the second and third quartiles, and the third category to the fourth quartile.

\section{Study of gene-gene/allele-allele interactions and risk of DS}

All the possible combinations between mutant genotypes at one or two loci (versus wild type genotypes) of MTHFR, MTRR, CBS, MTR, RFC1 and MTHFD genes were evaluated by a two-by-four table to assess the risk-excess due to the presence of two distinct mutant genotypes in the same woman. A significant positive interaction was found for the MTHFR 677TT genotype and the MTHFR 1298 CC or CA genotype ( $P=0.008$ by Fisher's exact test), the $1298 \mathrm{CC}$ or CA and the RFC1 GG or GA genotypes $(P=0.03)$, RFC1 $80 \mathrm{GG}$ and MTHFD 1958 AA genotypes ( $P=0.01$ by Fisher's exact test) (Table 4). No interactions were found between the remaining analyzed genotypes.

\section{Haplotype analysis}

A linkage disequilibrium between the MTHFR C677T and A1298C polymorphisms has been reported. ${ }^{33}$ Consistent with this observation, we performed a haplotype analysis. Table 5 shows a significant association between case-mothers and the T-C haplotype. It is worth noting that the MTHFR 677-1298 $\mathrm{T}-\mathrm{C}$ haplotype was present in our population, whereas it was absent in two previous studies. ${ }^{33,34}$ However, the T-C frequency is lower than the expected allele combination frequency (as calculated from the frequencies of each allele at positions 677 and 1298), confirming a negative selection of the T-C haplotype.
Table 4

Two-by-four table for gene-gene/allele-allele interactions

\begin{tabular}{|c|c|c|c|c|}
\hline $\begin{array}{l}\text { MTHFR } \\
677 \text { TT }\end{array}$ & $\begin{array}{c}\text { MTHFR } \\
1298 \text { CC } \\
\text { or CA }\end{array}$ & $\begin{array}{c}\text { Cases (\%) } \\
\mathrm{N}=94^{e}\end{array}$ & $\begin{array}{c}\text { Controls (\%) } \\
\mathrm{N}=256^{e}\end{array}$ & OR $(95 \% \mathrm{CI})$ \\
\hline+ & + & $6(6.4)$ & $3(1.2)$ & $7.20(1.36-47.24)^{a, c}$ \\
\hline- & + & $50(53.2)$ & $128(50.0)$ & $1.41(0.75-2.66)$ \\
\hline+ & - & $18(19.1)$ & $53(20.7)$ & $1.22(0.55-2.69)$ \\
\hline- & - & $20(21.3)$ & $72(28.1)$ & 1 (reference) \\
\hline $\begin{array}{l}\text { MTHFR } \\
1298 \text { CC } \\
\text { or CA }\end{array}$ & $\begin{array}{c}\text { RFC } 180 \\
\text { GG or } \\
\text { GA }\end{array}$ & $\begin{array}{c}\text { Cases (\%) } \\
\mathrm{N}=94^{e}\end{array}$ & $\begin{array}{c}\text { Controls (\%) } \\
\mathrm{N}=261^{e}\end{array}$ & OR $(95 \% \mathrm{CI})$ \\
\hline+ & + & $37(39.4)$ & $83(31.8)$ & $2.58(1.08-6.27)^{b, d}$ \\
\hline+ & - & $19(20.2)$ & $50(19.2)$ & $2.20(0.84-5.84)$ \\
\hline- & + & $29(30.8)$ & $76(29.1)$ & $2.20(0.91-5.49)$ \\
\hline- & - & $9(9.6)$ & $52(19.9)$ & 1 (reference) \\
\hline RFC180 GG & $\begin{array}{l}\text { MTHFD } \\
1958 \text { AA }\end{array}$ & $\begin{array}{c}\text { Cases }(\%) \\
\mathrm{N}=90^{e}\end{array}$ & $\begin{array}{l}\text { Controls (\%) } \\
\mathrm{N}=244^{e}\end{array}$ & OR $(95 \% \mathrm{CI})$ \\
\hline+ & + & $8(8.9)$ & $5(2.0)$ & $4.45(1.21-17.92)^{c, d}$ \\
\hline+ & - & $16(17.8)$ & $40(16.4)$ & $1.11(0.55-2.25)$ \\
\hline- & + & $11(12.2)$ & $46(18.9)$ & $0.67(0.30-1.44)$ \\
\hline- & - & $55(61.1)$ & $153(62.7)$ & 1 (reference) \\
\hline
\end{tabular}

${ }^{a} P=0.008 ;{ }^{b} P=0.03 ;{ }^{c} P=0.01$.

${ }^{d}$ The difference is significant using $P$-value adjusted for inflated error (adjusted $P=0.041$ ).

${ }^{e}$ The number refers to the total cases and controls analyzed for the distinct genotypes, as detailed in Table 2, and represents the total gene-gene/alleleallele interactions allowed by the sample group.

Table 5

MTHFR C677T and A1298C haplotype analysis

\begin{tabular}{lccccc}
\hline $\begin{array}{c}\text { Haplotype } \\
\text { 677-1298 }\end{array}$ & Frequency & $\begin{array}{c}\text { Case ratio } \\
\mathrm{N}=94\end{array}$ & $\begin{array}{c}\text { Control ratio } \\
\mathrm{N}=256\end{array}$ & $\chi^{2}$ & $\begin{array}{c}P \text { - } \\
\text { value }\end{array}$ \\
\hline T-C & 0.031 & $12 / 176$ & $10 / 502$ & 9.355 & 0.0022 \\
T-A & 0.436 & $76 / 112$ & $229 / 283$ & 1.09 & 0.2966 \\
C-C & 0.296 & $61 / 127$ & $146 / 366$ & 0.963 & 0.3265 \\
C-A & 0.237 & $39 / 149$ & $127 / 385$ & 1.184 & 0.2765 \\
\hline
\end{tabular}

MTHFR haplotype analysis performed by Haploview, version 3.2. ${ }^{31}$

Haplotypes were inferred only from subjects with complete genotyping data.

\section{Plasma tHcy levels}

Plasma tHcy levels were $8.6 \pm 4.3 \mu \mathrm{mol} / \mathrm{L}$ and $8.3 \pm 5.8$ $\mu \mathrm{mol} / \mathrm{L}$ in cases and controls, respectively. No significant difference was observed between the two groups $(P=0.69)$.

\section{DISCUSSION}

Down syndrome is the main genetic cause of mental retardation and a major public health concern. Despite the high incidence and social impact of DS, the available knowledge of its etiology and pathogenesis is incomplete. Since the first report by James et al. in $1999,{ }^{14}$ a wealth of studies have been 
conducted on the role of Hcy/folate metabolism in the pathogenesis of DS providing supporting evidence and new clues. ${ }^{15-24}$ However, the results greatly varied in the analyzed populations. The discordant data from subjects of distinct geographical regions may be explained by differences in the nutritional habits and genetic background of the populations. It is also reasonable that the weight of the single mutations is different according to ethnicity, thus pointing to the importance of selecting cases and controls within the same ethnic group. Accordingly, the present study explores the genetic risk profiles for DS and reports the analysis of seven polymorphic variants of genes of Hcy/folate metabolism, the gene-gene/allele-allele interactions among all polymorphisms and their association with maternal age at conception in a homogeneous population, providing the first evidence of genetic risk factors associated with advanced maternal age. Also, this is the first study investigating the role of the MTHFD G1958A polymorphism and of the MTHFR 677-1298 haplotypes in DS.

Our results provide evidence of a link between polymorphisms of genes of Hcy/folate pathway and increased risk of DS. In fact, the MTHFR 1298C and the RFC1 80G alleles were associated with increased risk of having a DS offspring; the risk was higher when the homozygous mutated genotype was analyzed. The MTHFR A1298C and the RFC1 A80G polymorphisms were shown to be genetic risk factors for DS in mothers belonging to the upper age-quartile of our data set. It has been proposed that chromosome 21 nondisjunctional process occurs more frequently with age progression as a consequence of an age-dependent derangement of meiosis-specific events. ${ }^{35} \mathrm{In}$ this case allelic variants, such as the ones affecting folate pathway, may functionally interact with other risk factors - as yet unidentified - to decrease the age-related surveillance for screening out aneuploid pregnancies. As risk factors may interact to produce a synergistic effect, we explored gene-gene interactions and found the first evidence of a positive interaction between the polymorphic variants of the MTHFR, RFC1 and MTHFD genes, while we could not confirm the interaction between MTHFR C677T and MTRR A66G found in other studies. ${ }^{15-18}$ These results provide further evidence for a major role of gene-gene interactions in the assessment of genetic susceptibility to DS. It can be hypothesized that blood folates and homocysteine levels influence the impact of the genotype. However in the case of the population analyzed in this study, results on total plasma homocysteine did not demonstrate a significant difference between DS-mothers and controls, pointing to a direct effect of certain genotypes as risk factors for DS. The haplotype analysis of the two polymorphic variants showed an association between cases and the MTHFR 6771298 T-C haplotype. Indeed, two distinct mutations in CIS position within the same gene can functionally interact to decrease enzyme activity resulting in a stronger effect on the observed phenotype. The data reported in this study are consistent with the original hypothesis that polymorphisms of genes of Hcy/folate pathway may predispose to chromosome 21 nondisjunctional errors. ${ }^{15-18,23}$ Our study failed to demonstrate an association of DS genetic risk with the MTHFR C677T variant, as reported elsewhere. ${ }^{14-17}$ This could be due either to an insufficient statistical power, or to a different weight of selected polymorphisms in distinct populations.

The present study bears some limitations. It is not population-based; however, we minimized potential bias affecting hospital-based case-control studies..$^{27,28}$ As most of the studies carried out so far, it has a low statistical power, an expected caveat of studies involving genotypes present at high frequency in the selected populations. In this scenario, while positive results are indicative of consistent evidence, it is not possible to rule out the contribution of a genetic variant to DS on the basis of negative results (type II error, beta). Given the evidence of discordant conclusions in studies of moderate genetic risk factors for DS in different geographic regions, the findings of the study may not be generalized to other populations. This study does not distinguish between meiosis I and meiosis II errors; in this regard, the investigation of folate pathway derangement during the meiotic phase would clarify whether the folate pathway genes, shown to be risk factors for DS, play a major role in one of the meiotic phases and may provide a rationale for preventive strategies based on preconceptional folic acid supplementation. Finally, only mothers with live DS conceptions are included in this study, which might miss a possible association between polymorphisms and fetal viability. In fact, genetic variants may give either a survival disadvantage or advantage, as reported by Hobbs and colleagues for a possible association of the MTHFR $677 \mathrm{~T}$ allele with survival advantage. ${ }^{36}$

Evidence of an impaired homocysteine-folate pathway associated with birth defects, such as neural tube and congenital heart abnormalities, has resulted in primary prevention measures based on folic acid fortification or supplementation. Studies on the prevalence of trisomy 21 following folic acid food fortification in USA and Canada failed to observe a reduced occurrence of DS. ${ }^{37,38,39}$ However, there are two issues to be taken into consideration in the prevention of DS by folic acid: the dose and the timing of folic acid intake. It has been proposed that genomic instability is kept at the minimum level when plasma folates exceed $34 \mathrm{nmol} / \mathrm{L}$ and plasma homocysteine is $<7.5 \mu \mathrm{mol} / \mathrm{L}$ : these concentrations are difficult to be achieved by daily folate intake of $<5 \mathrm{mg}$, a dose rarely provided by the current regimens of fortification and supplementation. ${ }^{40}$ Indeed, the recent report of a decreased occurrence of DS offspring in mothers supplemented with high doses of folic acid $(6 \mathrm{mg} / \text { day })^{41}$ is consistent with the above observations and with an involvement of the homocysteine-folate pathway in the etiology of DS. Concerning the timing of folate intake, it should be taken into account that maternal MI errors may occur in a time-frame starting in the fetal ovary during the grandmother's pregnancy and ending at ovulation, whereas MII errors occur at the time of fertilization. Therefore, it is likely that only MII errors would be immediately affected by folic acid intake in adult women, while a reduced occurrence of meiosis I errors may not be appreciated until the following generation. ${ }^{37}$

Data from this and other studies provide useful information for meta-analyses and underscore the relevance of gene combination studies in complex diseases such as Down syndrome. 


\section{ACKNOWLEDGMENTS}

We gratefully acknowledge the Associazione Sindrome di Down ONLUS Regione Campania and the women enrolled in the study for their support and collaboration. This study was supported by grant numbers 2002068222 and 2004062243 from MIUR-PRIN.

\section{References}

1. Morris JK, Wald NJ, Mutton DE, Alberman E. Comparison of models of maternal age-specific risk for Down syndrome live births. Prenat Diagn 2003;23:252-258.

2. Antonarakis SE, Petersen MB, McInnis MG, Adelsberger PA, et al. The meiotic stage of nondisjunction in trisomy 21: determination by using DNA polymorphisms. Am J Hum Genet 1992;50:544-550.

3. Jeanpierre M, Turleau C, Aurias A, Prieur M, et al. An embryonic-like methylation pattern of classical satellite DNA is observed in ICF syndrome. Hum Mol Genet 1993;2:731-735.

4. Harrison JJ, Anisowicz A, Gadi IG, Raffeld M, et al. Azacytidine-induced tumorigenesis of CHEF/18 cells: correlated DNA methylation and chromosome changes. Proc Natl Acad Sci U S A 1983;80:6606-6610.

5. Chen RZ, Pettersson U, Beard C, Jackson-Grusby L, et al. DNA hypomethylation leads to elevated mutation rates. Nature 1998;395:89-93.

6. Zhou ZS, Zhao G, Wan W. Current developments in biological methylations. Front Biotech Pharm 2001;2:199-217.

7. Fenech M. The role of folic acid and Vitamin B12 in genomic stability of human cells. Mutation Research 2001;475:57-67.

8. Frosst P, Blom HJ, Milos R, Goyette P, et al. A candidate genetic risk factor for vascular disease: a common mutation in methylenetetrahydrofolate reductase. Nat Genet 1995;10:111-113.

9. Castro R, Rivera I, Ravasco P, Camilo ME, et al. 5,10-methylenetetrahydrofolate reductase (MTHFR) $677 \mathrm{C}->$ T and 1298A->C mutations are associated with DNA hypomethylation. J Med Genet 2004;41:454-458.

10. Paz MF, Avila S, Fraga MF, Pollan M, et al. Germ-line variants in methyl-group metabolism genes and susceptibility to DNA methylation in normal tissues and human primary tumors. Cancer Res 2002;62:4519-4524.

11. Tsai MY, Yang F, Bignell M, Aras O, et al. Relation between plasma homocysteine concentration, the 844ins68 variant of the cystathionine beta-synthase gene, and pyridoxal-5' -phosphate concentration. Mol Genet Metab 1999;67:352-356.

12. Chango A, Emery-Fillon N, de Courcy GP, Lambert D, et al. A polymorphism (80G- $>A$ ) in the reduced folate carrier gene and its associations with folate status and homocysteinemia. Mol Genet Metab 2000;70:310-315.

13. Hol FA, van der Put NM, Geurds MP, Heil SG, et al. Molecular genetic analysis of the gene encoding the trifunctional enzyme MTHFD (methylenetetrahydrofolate-dehydrogenase, methenyltetrahydrofolate-cyclohydrolase, formyltetrahydrofolate synthetase) in patients with neural tube defects. Clin Genet 1998;53:119-125.

14. James SJ, Pogribna M, Pogribny IP, Melnyk S, et al. Abnormal folate metabolism and mutation in the methylenetetrahydrofolate reductase gene may be maternal risk factors for Down syndrome. Am J Clin Nutr 1999;70:495-501.

15. Hobbs CA, Sherman SL, Yi PHopkins SE, et al. Polymorphisms in genes involved in folate metabolism as maternal risk factors for Down syndrome. Am J Hum Genet 2000;67:623-630

16. Grillo LB, Acacio GL, Barini R, Pinto W, et al. Mutations in the methylene-tetrahydrofolate reductase gene and Down syndrome. Cad Saude Publica 2002;18:17951797.

17. da Silva LR, Vergani N, Galdieri Lde, C, Ribeiro Porto, MP, et al. Relationship between polymorphisms in genes involved in homocysteine metabolism and maternal risk for Down syndrome in Brazil. Am J Med Genet 2005;135:263-267.

18. O'Leary VB, Parle-McDermott A, Molloy AM, Kirke PN, et al. MTRR and MTHFR polymorphism: link to Down syndrome? Am J Med Genet 2002;107:151-155.

19. Chadefaux-Vekemans B, Coude M, Muller F. Methylenetetrahydrofolate reductase polymorphism in the etiology of Down Syndrome. Pediatr Res 2002;51:766-767.
20. Stuppia L, Gatta V, Gaspari AR, Antonucci I, et al. C677T mutation in the 5,10-MTHFR gene and risk of Down syndrome in Italy. Eur J Hum Genet 2002;10:388-390.

21. Boduroglu K, Alanay Y, Koldan B, Tuncbilek E. Methylenetetrahydrofolate reductase enzyme polymorphisms as maternal risk for Down syndrome among Turkish women. Am J Med Genet 2004;127:5-10.

22. Takamura N, Kondoh T, Ohgi S, Arisawa K, et al. Abnormal folic acid-homocysteine metabolism as maternal risk factors for Down syndrome in Japan. Eur J Nutr 2004;43:285-287.

23. Bosco P, Gueant-Rodriguez RM, Anello G, Barone C, et al. Methionine synthase (MTR) 2756 (A -> G) polymorphism, double heterozygosity methionine synthase 2756 AG/methionine synthase reductase (MTRR) 66 AG, and elevated homocysteinemia are three risk factors for having a child with Down syndrome. Am J Med Genet 2003;121:219-224.

24. Chango A, Fillon-Emery N, Mircher C, Blehaut H, et al. No association between common polymorphisms in genes of folate and homocysteine metabolism and the risk of Down's syndrome among French mothers. Br J Nutr 2005;94:166-169.

25. Brody LC, Conley M, Cox C, Kirke PN, et al. A polymorphism, R653Q, in the trifunctional enzyme methylenetetrahydrofolate dehydrogenase/methenyltetrahydrofolate cyclohydrolase/formyltetrahydrofolate synthetase is a maternal genetic risk factor for neural tube defects: report of the Birth Defects Research Group. Am J Hum Genet 2002;71:1207-1215.

26. Wilcken B, Bamforth F, Li Z, Zhu H, et al. Geographical and ethnic variation of the $677 \mathrm{C}>\mathrm{T}$ allele of 5,10 methylenetetrahydrofolate reductase (MTHFR): findings from over 7000 newborns from 16 areas world wide. J Med Genet 2003;40:619-625.

27. Wacholder S, Chatterjee N, Hartge P. Joint effect of genes and environment distorted by selection biases: implications for hospital-based case-control studies. Cancer Epidemiol Biomarkers Prev 2002;11:885-889.

28. Schulz KF, Grimes DA. Case-control studies: research in reverse. Lancet 2002;359: 431-434.

29. van der Put NMJ, Blom HJ. Replay to Donnelly. Am J Hum Genet 2000;66:744-745

30. Botto LD, Khoury MJ. Commentary: facing the challenge of gene-environment interaction: the two-by-four table and beyond. Am J Epidemiol 2001;153:1016-1020.

31. Barrett JC, Fry B, Maller J, Daly MJ. Haploview: analysis and visualization of LD and haplotype maps. Bioinformatics 2005;21:263-265

32. Keppel G. Design and analysis: A researcher's handbook ( $3^{\text {rd }}$ Edition). Englewood Cliffs, NJ: Prentice Hall; 1991

33. Stegmann K, Ziegler A, Ngo ET, Kohlschmidt N, et al. Linkage disequilibrium of MTHFR genotypes 677C/T-1298A/C in the German population and association studies in probands with neural tube defects (NTD). Am J Med Genet 1999;87:23-29.

34. Urano W, Taniguchi A, Yamanaka H, Tanaka E, et al. Polymorphisms in the meth ylenetetrahydrofolate reductase gene were associated with both the efficacy and the toxicity of methotrexate used for the treatment of rheumatoid arthritis, as evidenced by single locus and haplotype analyses. Pharmacogenetics 2002;12:183-190.

35. Hassold T, Sherman S. Down syndrome: genetic recombination and the origin of the extra chromosome 21. Clin Genet 2000;57:95-100.

36. Hobbs CA, Cleves MA, Lauer RM, Burns TL, et al. Preferential transmission of the MTHFR $677 \mathrm{~T}$ allele to infants with Down syndrome: implications for a survival advantage. Am J Med Genet 2002;113:9-14.

37. Ray JG, Meier C, Vermeulen MJ, Cole DE, et al. Prevalence of trisomy 21 following folic acid food fortification. Am J Med Genet A 2003;120:309-313.

38. Simmons CJ, Mosley BS, Fulton-Bond CA, Hobbs CA. Birth defects in Arkansas: is folic acid fortification making a difference? Birth Defects Res A Clin Mol Teratol 2004;70:559-564.

39. Canfield MA, Collins JS, Botto LD, Williams LJ, et al. National Birth Defects Preventing Network. Changes in the birth prevalence of selected birth defects after grain fortification with folic acid in the United States: findings from a multi-state population-based study. Birth Defects Res A Clin Mol Teratol 2005;73:679-689.

40. Fenech M. Recommended dietary allowances (RDAs) for genomic stability. Mutat Res 2001;480-481:51-4.

41. Czeizel AE, Puho E. Maternal use of nutritional supplements during the first month of pregnancy and decreased risk of Down's syndrome: case-control study. Nutrition 2005;21:698-704. 